\title{
Влияние слияний и поглощений на операционную эффективность компаний на развивающихся рынках капитала
}

\author{
Григорьева С.А. ${ }^{9}$, Троицкий П.В. ${ }^{10}$
}

В статье представлены результаты исследования эффективности сделок по передаче корпоративного контроля на выборке компаний стран БРИК в период с 2005 по 2009 год. Основываясь на методе анализа финансовой отчетности, мы обнаружили рост операчионных показателей компаний (EBITDA/Sales) в результате сделок слияний $u$ поглощений спустя два года после их завершения. Основными детерминантами эффективности сделок, инициированными компаниями из стран БРИК, являются: размер компании-покупателя и дружественная направленность сделки.

\section{JEL: $G 34$}

Ключевые слова: слияния и поглощения, эффективность деятельности компании, развивающиеся рынки капитала, операџионная эффективность

Современные тенденции развития экономики, характеризующиеся усилением конкуренции и глобализацией рынков, приводят к значительному росту слияний и поглощений (M\&A). Все более значимую роль в данных процессах начинают играть компании с развивающихся рынков капитала. Способствуют ли сделки M\&A созданию стоимости компаний или являются лишь удобным способом для менеджмента по расширению и укреплению своих позиций? В имеющихся эмпирических исследованиях выявляются противоположные точки зрения о влиянии M\&A на стоимость компаний. Подавляющее большинство работ сосредоточено на эффектах слияний и поглощений на развитых рынках капитала, тогда как последствия сделок на развивающихся рынках изучены значительно меньше. В данной статье мы представляем результаты эмпирического исследования, построенного по данным компаний стран БРИК. В первую очередь мы приводим обзор наиболее значимых исследований, изучающих влияние сделок слияний и поглощений на эффективность деятельности компаний с развитых и развивающихся рынков капитала. На следующем шаге мы описываем модель исследования и процесс формирования выборки. Далее приводим основные результаты проведенного исследования и обсуждаем возможные направления для дальнейшего научного поиска.

\section{Результаты эмпирических исследований влияния слияний и поглощений на эффективность деятельности компаний}

Обзор научных исследований, проводимых на данных компаний с развитых рынков капитала, позволяет выделить следующие методы, использующиеся для оценки эффективности M\&A: метод накопленной избыточной доходности (event study analysis), анализ финансовой отчетности (accounting studies), опросы менеджеров (surveys of executives), разбор конкретных ситуаций (clinical studies) (Bruner, 2001; Lu, 2008). Для проведения эмпирических исследований наиболее часто используют два первых метода. Метод накопленной избыточной доходности основан на изучении реакции фондового рынка на объявления о слияниях и/или поглощениях и позволяет оценить влияние сделок на стоимость компаний в краткосрочной перспективе (как правило, до года). Анализ финансовой отчетности предполагает сравнение финансовых показателей компаний -

\footnotetext{
${ }^{9}$ Старший преподаватель кафедры экономики и финансов фирмы факультета экономики НИУ ВШЭ.

${ }^{10}$ Выпускник магистерской программы «Корпоративные финансы» НИУ ВШЭ.
} 
участников сделки за определенный период до и после ее завершения, т.е. позволяет определить операционную эффективность сделок М\&A в долгосрочной перспективе (как правило, более одного года). Основным источником информации в данном случае является не фондовый рынок, а финансовая отчетность компаний по определенным стандартам финансовой отчетности. Наиболее часто используемые финансовые показатели - OCF/TMV (operating cash flow/total market value of assets - операционный денежный поток/рыночная стоимость активов), ROA (return on assets - доходность активов), ROE (return on equity доходность собственного капитала), EBITDA/Sales (прибыль до вычета процентов, налогов и амортизации/выручка) и другие.

Результаты зарубежных исследований, построенных на основе метода накопленной избыточной доходности, свидетельствуют о том, что компании-цели, как правило, выигрывают в результате сделок M\&A. Значения накопленной избыточной доходности в наиболее поздних работах варьируют от 7 до 42\%, независимо от размера выборки, выбранного окна события и исследуемого временного периода (Schwert, 1996; Maquieira et al., 1998; Eckbo, Thorburn, 2000; Goergen, Renneboog, 2003; Billett et al., 2003; Campa, Hernando, 2004). Доходность для компаний-покупателей не столь однозначна. Ее значения в различных работах могут быть как положительными, так и отрицательными или равняться нулю (Loderer, Martin, 1990; Baker, Limmack, 2002; Walker, 2000; Moeller et al., 2005, 2007; Bradley, Sundaram, 2006; Betton et al., 2008; Hackbarth, Morrelec, 2008; Hamza, 2009). Объяснением подобных расхождений могут выступать различия в требованиях к формированию выборки исследования, период наблюдения, а также выбранный метод прогнозирования нормальной доходности акций.

Результаты наиболее поздних и важных эмпирических работ, исследующих операционную эффективность сделок M\&A на основе метода анализа финансовой отчетности, суммированы в приложении к данной статье. Исследования, использующие в качестве финансовых показателей компаний - показатели, основанные на денежных потоках, как правило, свидетельствуют об улучшении операционной эффективности компаний в результате сделок M\&A, в то время как исследования, базирующиеся на показателях, основанных на прибыли и доходности компаний (ROA, ROE, EPS и др.), доказывают ее снижение вследствие сделок. Это может свидетельствовать о том, что правила ведения бухгалтерского учета в компаниях могут искажать показатели эффективности и вести к отрицательной оценке M\&A. Причинами расхождения результатов эмпирических исследований также могут быть различия в экономической ситуации стран компанийучастников сделки, особенностях ведения бухгалтерского и налогового учета в разных странах, размере изучаемой выборки, во временном периоде исследования, выбранных финансовых показателях и применяемой методологии исследования (Sudarsanam, 2003; Bruner, 2004).

Размер выборки в современных работах колеблется от 20 сделок (Tsung-Ming, Hoshino, 2000), до 859 (Heron, Lie, 2002). Если более ранние исследования в основном анализировали данные по США, то в последнее время наблюдается все больше работ, построенных по данным компаний Европы и других стран. Также постепенно увеличилось время наблюдения в связи с улучшением регулярности и точности статистических данных - от 1 года до 10 лет. Хотя последнее - скорее исключение из правил, основная масса исследований ведется на протяжении 3-5 лет (на данные финансовой отчетности влияет большое количество разнообразных внешних событий, при большом временном интервале необходимы поправки на эти события, которые не всегда возможно как обосновать, так и применить).

Относительно методов анализа данных, а также изучаемых показателей - наблюдается достаточно большое различие между исследованиями. Например, Хейли и др. (Healy et al., 1992) определяют эффективность через расчет операционного денежного потока до налогов к рыночной стоимости активов компании , Рейвенскрафт и Шерер (Ravencraft, Sherer, 1989) через сравнение основных финансовых показателей (операционный доход EBIT), денежный поток, масштабированные на чистые активы на конец года или выручку), Герман и 
Левенштайн (Herman, Lowenstein, 2008) - пошли тем же путем, проанализировав доходность капитала компании (return on capital, ROC), но анализируемая ими выборка состояла из враждебных сделок M\&A. Такие показатели, как доходность активов (ROA) и доходность собственного капитала (ROE), рентабельность продаж (profit margin, PM) рассматриваются в работах Шарма, Хо и Тсунг-минг и Хошино (Sharma, Ho, 2002; Tsung-Ming, Hoshino, 2000). В последнее время появляются работы изучающие изменение показателя экономической добавленной стоимости (economic value added, EVA) вследствие сделок M\&A (Yook, 2004; Sudarsanam, 2003).

Исследования эффективности слияний и поглощений проводились в основном на развитых рынках капитала, в то время как последствия сделок на развивающихся рынках изучены значительно меньше. Согласно утверждению Кханна, Палепу (Khanna, Palepu, 1997, 2000), стратегия интеграции может быть более эффективной именно на данных рынках в силу неразвитости институциональной среды. Проверке данной гипотезы было посвящено всего несколько академических работ, основанных на данных Словении, Польши, Китая, Индии и Турции (Pawaskar, 2001; Trojanowski, 2002; Beena, 2004; Gregoric, Vespro, 2009; Pop, 2006; Changqi, Ningling, 2010; Ho-Mou Wu, 2009; Mantravadi, Reddy, 2008).

Исследуя реакцию фондового рынка на объявления о 53 слияниях и поглощениях на рынке Польши в период с 1996 по 2000 год, Тродженовски (Trojanowski, 2002) получил положительные $(+1,16 \%)$ статистически значимые (на 5\%-ном уровне значимости) значения накопленной избыточной доходности. Положительная реакция фондового рынка на объявления о сделках M\&A также была обнаружена в работе Грегорик, Веспро (Gregoric, Vespro, 2009), изучающих эффективность сделок на рынке Словении. Необходимо отметить, что в данных исследованиях анализировались сделки по продаже пакетов акций от 5 до 25\%. Доля продаваемых акций была ограничена 25\%, так как при превышении данного уровня покупатели обязаны делать предложение о покупке остальных акций компании по законодательству рассматриваемых в исследованиях стран. Таким образом, в работах изучались сделки, не предполагающие перехода контрольного пакета акций, что отличает их от большинства работ, исследующих эффективность сделок М\&A.

В отличие от результатов, указывающих на то, что компании-цели чаще всего выигрывают в сделках M\&A на развитых рынках капитала, Поп обнаружил, что в среднем значения накопленной избыточной доходности для компаний Румынии равны нулю (Рор, 2006).

Изучая реакцию фондового рынка на объявления о 128 сделках M\&A в период с 2000 по апрель 2008 года на развивающихся рынках капитала, Е.В. Чиркова, Е.В. Чувствина (Чиркова, Чувствина, 2011) обнаружили, что рынок по-разному реагирует на сделки по приобретению публичных и частных компаний, при этом более благосклонно оценивает приобретение последних. Авторы также попытались объяснить причины найденной разницы путем изучения влияния различных факторов на показатели накопленной избыточной доходности: активность рынка корпоративного контроля, способ финансирования сделки, приобретаемую долю компании-цели и другие.

Исследование влияния сделок M\&A на операционную эффективность компаний предсталено в работе Мантравади, Редди (Mantravadi, Reddy, 2008). На основе изучения выборки из 118 сделок M\&A, инициированных компаниями Индии, в период с 1991 по 2003 год, авторы заключили, что слияния и поглощения в среднем ведут к снижению показателей рентабельности и доходности инвестированного капитала (return on capital employed, ROCE) для компаний-покупателей спустя три года после завершения сделок. Авторы также обнаружили, что отраслевая принадлежность компаний оказывает влияние на изменение изучаемых финансовых показателей. Полученные результаты согласуются с выводами работы Биены (Beena, 2004), основанными на анализе 115 компаний-покупателей Индии в период с 1995 по 2000 год и противоречат результатам исследования Паваскара (Pawaskar, 2001), которое доказывает рост показателей эффективности 36 компаний-покупателей в период с 1992 по 1995 год. 
Одновременному использованию метода событий и анализу финансовой отчетности посвящена работа Хо-Мa By (Ho-Mou $\mathrm{Wu}, 2007)$. В ней автор рассматривает сделки М\&A 1086 компаний (1363 транзакций) в период с 2004 по 2005 год, размещенных на Шанхайской и Шенженьской фондовой биржах. Кроме рассмотрения непосредственно эффективности автор пытается выявить определяющие факторы последней: состояние фондового рынка (растущий/падающий), год осуществления сделки, структуру собственности (инициированные государственной/частной компанией). Полученные автором отрицательные значения накопленной избыточной доходности в 2004 году свидетельствуют о разрушении стоимости компаний в результате сделок M\&A. При разделении выборки на сделки, осуществленные государственными и частными компаниями, было обнаружено, что накопленная избыточная доходность отрицательна для первых и положительна для вторых. В 2005 году избыточная доходность положительна как для государственных $(1,83 \%)$, так и для частных компаний $(1,11 \%)$. Эффективность сделок M\&A в 2005 году также подтверждает рост финансовых показателей компаний - участников сделки (EPS, EBIT, FCF, OCF, ROA, ROE).

Противоположность выводов эмпирических работ, небольшое количество исследований, построенных на данных отдельных развивающихся стран, вызывают необходимость дальнейшего изучения эффективности сделок М\&A, а также выявления факторов, ее определяющих.

\section{Влияние сделок слияний и поглощений на операционную эффективность компаний стран БРИК}

\section{Модель и гипотезы исследования}

Эмпирический анализ основывается на методе анализа финансовой отчетности. Данный метод позволяет оценить эффективность сделок М\&A на долгосрочном временном горизонте. Таким образом, данная работа развивает исследование влияния сделок М\&А на эффективность деятельности компаний стран БРИК, представленное в работе С.А. Григорьевой (Григорьева, 2011), и выполненное с использованием метода накопленной избыточной доходности.

Для измерения операционной эффективности сделок М\&A использовался показатель EBITDA/Sales (EBITDA к выручке). EBITDA был выбран в качестве прокси-показателя операционного денежного потока (Operating cash flow) ${ }^{11}$, изучаемого в большинстве исследований на развитых рынках капитала (Healy et al., 1992; Switzer, 1996; Ghosh, 2001). В отличие от чистой прибыли, данные показатели не зависят от метода учета приобретений и способа финансирования сделки, поэтому их использование является наиболее целесообразным (Healy et al., 1992).

Метод анализа финансовой отчетности предполагает сравнение изучаемого показателя до и после интеграции компаний. Окно исследования в данной работе составило четыре года, $[-2 ;+2]$, т.е. рассматривалась бухгалтерская отчетность компаний за два года до и после завершения сделки.

В существующих эмпирических работах используются различные варианты окон, от [$1 ;+1]$ до $[-5 ;+5]$ лет. Окно длинной три года слишком мало, чтобы закончилась реорганизация в связи с заключенной сделкой и компания начала работать как единый механизм. Десятилетнее окно наблюдения представляется слишком большим, так как за данный период может произойти ряд событий, которые способны оказать более весомое влияние на финансовую отчетность компаний, нежели изучаемая сделка M\&A. Кроме того, при проведении исследования на развивающихся рынках капитала использование длинных

\footnotetext{
${ }^{11}$ Operating cash flow (операционный денежный поток) = sales (выручка) - cost of goods sold and administrative expenses (себестоимость и административные расходы) + depreciation (амортизация) + goodwill expenses (гудвилл).
} 
окон приводит к значительному сокращению выборки вследствие недоступности данных по большому количеству компаний. Таким образом, в работе был выбран интервал $[-2 ;+2]$ года.

Для оценки эффективности сделок M\&A в данном исследовании используется модель, учитывающая корректировку на отрасль, предложенная Хейли и др. (Healy et al., 1992) и пользующаяся популярностью у ряда других исследователей (Switzer, 1996; Moeller and Schlingemann, 2004; Rahman \& Limmack, 2004; Powell \& Stark, 2005):

(1)

$$
\left(\frac{\text { EBITDA }}{\text { Sales }}\right)_{\text {after }, i}^{\text {ind }}=\alpha+\beta\left(\frac{\text { EBITDA }}{\text { Sales }}\right)_{\text {synthetic (before }), i}^{\text {ind }}+\varepsilon_{i}
$$

где:

$\left(\frac{\text { EBITDA }}{\text { Sales }}\right)_{\text {after }, i}^{\text {ind }}$

- скорректированное на отрасль значение EBITDA/Sales объединенной компании i, спустя два года после завершения сделки;

$$
\left(\frac{\text { EBITDA }}{\text { Sales }}\right)_{\text {synthetic(before }), i}^{\text {ind }}
$$

- скорректированное на отрасль синтетическое значение EBITDA/Sales для компании-покупателя и компании-цели за два года до сделки M\&A;

$\alpha$ - отражает изменение EBITDA/Sales компаний (аномальная EBITDA/Sales, не зависящая от значения EBITDA/Sales до сделки) - критерий эффективности сделок M\&A;

$\beta$ - отражает корреляцию между EBITDA/BVAssets до и после сделки M\&A.

Поправка на отрасль осуществлялась путем корректировки показателя $\left(\frac{\text { EBITDA }}{\text { Sales }}\right)$ компаний - участников сделок на соответствующее медианное значение показателя для той или иной отрасли.

Описанная модель позволяет протестировать следующую гипотезу на выборке стан группы БРИК:

Гипотеза 1: Сделки слияний и поглощений в странах группы БРИК не ведут к снижению операционной эффективности компаний - участников сделок:

$$
\left(\frac{\text { EBITDA }}{\text { Sales }}\right)_{\text {after }}^{\text {ind }} \geq\left(\frac{\text { EBITDA }}{\text { Sales }}\right)_{\text {synthetic(before). }}^{\text {ind }}
$$

\section{Характеристика выборки}

Для проведения исследования нами были выбраны четыре наиболее перспективные растущие рынки - Бразилия, Россия, Индия, Китай, составляющие группу БРИК. В 2001 году Джим O’Нил, главный экономист Goldman Sachs, предложил аббревиатуру БРИК, составленную из начальных букв названий вышеназванных стран. Эти страны рассматривались им как наиболее важные и перспективные, способные влиять на тенденции развития мировой экономики.

При формировании выборки сделок нами была использована база данных Zephyr, бюро Van Dijk и ресурсы Bloomberg.

В исследуемую выборку вошли сделки M\&A, завершенные в период с 2005 по 2009 год. Выбранный временной интервал представляет собой максимальный период времени, для которого можно было осуществить поиск необходимой финансовой информации для большинства компаний.

Для формирования итоговой выборки исследования были введены следующие критерии:

1. Статус сделки. Нами были включены в рассмотрение завершенные сделки. 
2. Размер приобретаемого пакета. В конечную выборку включались сделки, в результате совершения которых был консолидирован контрольный пакет акций (50\%), дающий неоспоримое право на управление финансовыми потоками компании.

3. Объем сделки. Большое значение при анализе сделок слияния/поглощения имеет объем совершенной сделки. Включение в исследование «маленьких» сделок априори привело бы к незначимому влиянию сделки на операционные показатели компаний. С нашей точки зрения, оптимальным пороговым значением является размер сделки, составляющий не менее 7\% от капитализации компании-покупателя.

4. Характеристики компаний - участников сделки. В выборку включались публичные компании, финансовая отчетность которых находилась в открытом доступе и необходимые данные о которых могли быть получены из указанных выше баз данных. Мы контролировали единство стандартов финансовой отчетности, оставляя в выборке лишь те компании, которые применяли правила и принципы МСФО. Из рассмотрения исключались фирмы, оперирующие в финансовом секторе, и регулируемые компании, поскольку к ним неприменимы стандартные методы оценки стоимости. Из выборки были элиминированы компании, участвующие в нескольких крупных сделках M\&A.

В выбранный период времени в странах БРИК было совершено 307 сделок M\&A, подходящих под критерии 1-3. По причине отсутствия данных по анализируемым показателям выборка была сокращена до 61 сделки M\&A. Оказалось, что 52 транзакции (85\% от общей выборки) представляют собой дружественные сделки, совершенные в рамках одной отрасли. В 70\% случаев оплата производилась денежными средствами.

\section{Эмпирические тесты и результаты}

В таблице 1 представлены результаты анализа операционной эффективности сделок М\&А в странах БРИК.

Таблица 1

Результаты анализа операционной эффективности сделок M\&A, инициированных компаниями из стран БРИК

\begin{tabular}{|c|c|c|c|c|}
\hline & $\alpha$ & $\beta$ & $\mathrm{R}^{2}$ & F-стат \\
\hline $\begin{array}{l}\text { Скорректированньій } \\
\text { после } M \& A\end{array}$ & на отрасль & атель ол & ной э & ффективности спустя 2 года \\
\hline EBITDA/Sales & $\begin{array}{l}0,060 * * \\
(0,03)\end{array}$ & $\begin{array}{l}0,699 * * * \\
(0,00)\end{array}$ & 0,43 & 0,00 \\
\hline $\begin{array}{ll}* * * & \text { результат значим } \\
* * & \text { результат значим } \\
* & \text { результат значим }\end{array}$ & $\begin{array}{l}\text { на } 1 \% \text {-ном ур } \\
\text { на } 5 \% \text {-ном ур } \\
\text { на } 10 \% \text {-ном у }\end{array}$ & & & Значения в скобках - (p-value) \\
\hline
\end{tabular}

Как видно из таблицы 1 , значение $\alpha$ является положительным для четырехлетнего периода, [-2;+2] года, и статистически значимым на уровне $5 \%$. Полученный результат свидетельствует о росте операционной эффективности компаний в результате сделок М\&А. Таким образом, тестируемая нами гипотеза 1 не может быть отвергнута на 5\%-ном уровне значимости для сделок слияний и поглощений, инициируемых компаниями из стран БРИК. Ввиду того что рассматриваемый в исследовании период включает мировой финансовый кризис, который мог существенно повлиять на операционную эффективность компаний участниц сделок, нами была введена в модель дамми-переменная CRISIS, принимающая значение 1 , если хотя бы один год из окна исследования приходился на кризисный период, и 0 - в противном случае. Полученные результаты показали незначимость коэффициента при введенной дамми-переменной, что может объясняться небольшим количеством сделок, приходящимся на этот период, а также введением поправки на отрасль.

Полученные результаты согласуются с выводами исследователей Хейли и др., Мартыновой и др., Пауэлла, Старка по компаниям США и Европы, с выводами Паваскара по 
компаниям Индии и протеворечат результатам Мантравади, Редди, изучающих операционную эффективность индийских компаний-покупателей (Healy et al., 1992, Martynova M. et al., Powell, Stark, 2005, Pawaskar, 2001, Mantravadi, Reddy, 2008). Необходимо отметить, что Мантравади, Редди изучали внутристрановые сделки в Индии в период с 1991 по 2003 год и не осуществляли поправку на отрасль.

Следующим направлением исследования стало выявление основных детерминант, оказывающих влияние на эффективность сделок M\&A. В качестве возможных детерминант эффективности сделок М\&A в научной литературе обычно рассматривают: метод финансирования сделки, значение Q Тобина, финансовый рычаг, размер сделки, уровень инвестирования в исследования и разработки, дружественность сделки, связанность бизнесов объединяющихся компаний, а также различные показатели качества корпоративного управления компаний (Swanstorm, 2006; Masulis et al., 2006; Moeller et al., 2004 Glegg et al., 2010). Также в последние годы наблюдается рост числа исследований, направленных на изучение влияния на эффективность сделок M\&A факторов, отличных от экономических культурных (Cartwright, 2005; Schoenberg, 2000) и социальных различий (Bartels et. al., 2006), организационной структуры (Haslam, Ellemers, 2005) и других.

В данном исследовании изучалось влияние характеристик сделок M\&A на их эффективность. Основываясь на собранной информации, в работе тестировалась следующая итоговая модель:

(2)

$\left(\frac{\text { EBITDA }}{\text { Sales }}\right)_{\text {after }, i}^{\text {ind }}=\alpha+\beta_{1}\left(\frac{\text { EBITDA }}{\text { Sales }}\right)_{\text {synthetic(before }, i}^{\text {ind }}+\beta_{2}($ DEALSIZE $)+\beta_{3}(F R E N)+\beta_{4}(D A T E)+\varepsilon_{i}$

Независимые переменные, представляющие собой возможные детерминанты операционной эффективности, обобщены в таблице 2.

Таблица 2

Независимые переменные в модели анализа детерминант операционной эффективности сделок М\&A

\begin{tabular}{|l|l|}
\hline \multicolumn{1}{|c|}{ Обозначение } & \multicolumn{1}{|c|}{ Описание и способ расчета } \\
\hline DEAL SIZE & $\begin{array}{l}\text { Размер сделки. Рассчитывается как отношение стоимости сделки к } \\
\text { рыночной капитализации компании-покупателя }\end{array}$ \\
\hline FREN & $\begin{array}{l}\text { Дамми-переменная, принимающая значение 1, если сделка } \\
\text { дружественная, и 0-если нет }\end{array}$ \\
\hline DATE & $\begin{array}{l}\text { Дамми-переменная, принимающая значение 1, если сделка была } \\
\text { завершена в том же году, в котором о ней было объялено, и 0 -в } \\
\text { противном случае }\end{array}$ \\
\hline
\end{tabular}

Перед тестированием гипотез о значимости факторов предложенная модель была проверена на наличие мультиколлинеарности с помощью VIF и гетероскедастичности с помощью тестов Уайта и Глейзера. Для всех регрессоров значения VIF оказались меньше 3, что говорит об отсутствии мультиколлинеарности. Проводимые тесты на гетероскедастичность на уровне значимости 0,05 ее не выявили.

Результаты проведенного регрессионного анализа, представленные в таблице 3, свидетельствуют о двух факторах, оказывающих статистически значимое влияние на операционную эффективность сделок, - DEAL SIZE (значение -0,11) на уровне значимости $10 \%$, FREN (значение $+0,09$ ) на уровне значимости $10 \%$. 
Выявление факторов операционной эффективности сделок M\&A

\begin{tabular}{lc}
\hline Переменная & $\begin{array}{c}\text { Значение коэффициента } \\
\text { (t-статистика) }\end{array}$ \\
\hline Intercept & 0,09 \\
$\left(\frac{\text { EBITDA }}{\text { Sales }}\right)_{\text {synthetic(before),i }}^{\text {ind }}$ & $\left(1,91^{* *}\right)$ \\
DEALSIZE & 0,698 \\
& $\left(6,99^{* * *}\right)$ \\
FREN & -0.11 \\
& $\left(-1,88^{*}\right)$ \\
DATE & 0.09 \\
\end{tabular}

Количество наблюдений 61

$\mathrm{R}^{2} 0.53$

*** значимо на уровне $1 \%$

** значимо на уровне 5\%

* значимо на уровне $10 \%$

Отрицательная зависимость размера сделки (DEALSIZE) с операционной эффективностью может свидетельствовать о систематической переплате компаниямипокупателями при слияниях и поглощениях, что частично подтверждает теорию гордыни Ролла (Roll, 1986). Кроме того, приобретение относительно маленьких компаний реализовать легче, поэтому вероятность положительного исхода сделки высока (Anslinger et al., 1996).

Положительная зависимость показателя FREN и операционной эффективности сделок говорит о том, что при дружественных сделках компании-покупатели, как правило, обладают более полной информацией относительно деятельности и финансового состояния компаниицели, кроме того, и управляющие компанией не препятствуют сделке, что экономит существенные средства приобретаемой компании и положительно влияет на операционную деятельность компании после сделки.

Полученные результаты согласуются с выводами исследования Рамасвами и Вегелейн, которые также получили отрицательную зависимость между операционной эффективностью и размером сделки (SIZE), и положительную зависимость с дружественным характером слияния (FREN) (Ramaswamy, Waegelein, 2003).

На изучаемой выборке удалось выявить только два фактора, оказывающих влияние на операционную эффективность сделок М\&A. Включение в анализ дополнительных детерминант, связанных с характеристиками сделок М\&A (способом финансирования, связанностью бизнесов сливающихся компаний, международной направленностью транзакций) привели к незначимым результатам.

\section{Выводы}

В результате эмпирического исследования на выборке компаний стран БРИК было выявлено, что сделки слияний и поглощений ведут к росту операционной эффективности компаний - участниц сделки. Полученные результаты согласуются с выводами ряда работ, построенных на данных компаний с развитых и развивающихся рынков капитала (Healy et al., 1992; Switzer, 1996; Powell, Stark, 2005; Pawaskar, 2001). В качестве факторов, оказывающих значимое влияние на операционную эффективность сделок, были выявлены: размер заключаемой сделки и дружественная направленность M\&A.

Проведенное исследование не претендует на полноту и детальность в отношении изучаемого вопроса по причине небольшого количества наблюдений в выборке, существования определенной доли субъективизма при ее формировании и ограниченности 
информации, необходимой для выявления факторов эффективности сделок М\&A. Отмеченные недостатки открывают возможности для дальнейшего научного поиска.

В данном исследовании мы концентрировались на изучении операционной эффективности сделок М\&A на долгосрочном временном горизонте, изучая финансовую отчетность компаний - участниц сделки. Улучшение операционной эффективности компаний не означает рост ее стоимости в долгосрочном периоде. Поэтому следующим шагом в исследовании эффективности сделок слияний и поглощений может быть изучение их влияния на стоимость компании на основе анализа экономической прибыли за несколько лет до и после проведения сделки M\&A. Развитие данного исследования возможно и по нескольким другим направлениям: во-первых, требуют дальнейших исследований вопросы влияния на стоимость компаний различных типов M\&A (горизонтальные, вертикальные, конгломеративные). Данные аспекты почти не раскрыты в эмпирических исследованиях на развивающихся рынках капитала. Во-вторых, практически не разработанным вопросом в имеющихся академических публикациях является исследование результатов международных сделок M\&A, предпринятых компаниями из развивающихся стран. В-третьих, исследование операционной эффективности может быть осуществлено на выборке большего количества развивающихся стран и с использованием более широкого спектра финансовых показателей.

Приложение

Обобщение результатов исследований операционной эффективности сделок M\&A на

развитых рынках капитала

\begin{tabular}{|c|c|c|c|c|}
\hline Исследование & \begin{tabular}{|c|} 
Период \\
исследования, \\
размер выборки, \\
страна \\
\end{tabular} & $\begin{array}{c}\text { Показатель } \\
\text { операционной } \\
\text { эффективности }\end{array}$ & $\begin{array}{c}\text { Корректировка } \\
\text { операционного } \\
\text { показателя на } \\
\text { отрасль } \\
\end{array}$ & Основные выводы \\
\hline $\begin{array}{l}\text { Healy, Palepu, } \\
\text { Ruback, } 1992\end{array}$ & $\begin{array}{l}\text { 1979-1984; } \\
50 \text { крупных } \\
\text { слияний; США }\end{array}$ & $\begin{array}{l}\text { Операционный } \\
\text { денежный поток до } \\
\text { налогов к рыночной } \\
\text { стоимости активов (pre- } \\
\text { tax operating cash flow to } \\
\text { TMV) }\end{array}$ & $\begin{array}{l}\text { Отрасль; } \\
\text { контроль за } \\
\text { стандартами } \\
\text { финансовой } \\
\text { отчетности }\end{array}$ & $\begin{array}{l}\text { Значимые улучшения } \\
\text { операционной } \\
\text { эффективности; } \\
\text { положительная связь } \\
\text { между избыточной } \\
\text { доходностью и } \\
\text { показателями } \\
\text { операционной } \\
\text { эффективности }\end{array}$ \\
\hline $\begin{array}{l}\text { Manson, Stark, } \\
\text { Thomas, } 1994\end{array}$ & $\begin{array}{l}1985-1987, \\
38 \text { приобретений; } \\
\text { Великобритания }\end{array}$ & $\begin{array}{l}\text { Операционный } \\
\text { денежный поток к } \\
\text { рыночной стоимости } \\
\text { компании } \\
\text { (operating cash flow to } \\
\text { total market value of firm) }\end{array}$ & Отрасль & $\begin{array}{l}\text { Рост операционной } \\
\text { эффективности и } \\
\text { положительная связь с } \\
\text { доходностью для } \\
\text { акционеров }\end{array}$ \\
\hline $\begin{array}{l}\text { Switzer, } \\
1996\end{array}$ & $\begin{array}{l}\text { 1967-1987; } \\
324 \\
\text { приобретений; } \\
\text { США }\end{array}$ & $\begin{array}{l}\text { Операционной денежный } \\
\text { поток до налогов к } \\
\text { рыночной стоимости } \\
\text { активов (pre-tax operating } \\
\text { cash flow to TMV) }\end{array}$ & Отрасль & $\begin{array}{l}\text { Значимые улучшения в } \\
\text { операционной } \\
\text { эффективности компаний } \\
\text { - участниц сделки }\end{array}$ \\
\hline $\begin{array}{l}\text { Tsung-Ming, } \\
\text { Hoshino, } 2000\end{array}$ & $\begin{array}{l}\text { 1987-1992; } \\
20 \text { приобретений; } \\
\text { Тайвань }\end{array}$ & $\begin{array}{l}\text { ROA, ROE, финансовый } \\
\text { рычаг, ликвидность, рост } \\
\text { продаж (financial } \\
\text { leverage, liquidity ratios, } \\
\text { sales growth) }\end{array}$ & Отрасль & $\begin{array}{l}\text { Положительная реакция } \\
\text { фондового рынка на } \\
\text { М\&А; снижение } \\
\text { операционных } \\
\text { показателей компаний- } \\
\text { покупателей в результате } \\
\text { сделок; отсутствие } \\
\text { корреляции между } \\
\text { накопленной избыточной } \\
\text { доходностью и } \\
\text { операционными } \\
\text { показателями компаний }\end{array}$ \\
\hline Ghosh, 2001 & 1981-1995; & Операционный & Эффективность & Не обнаружено значимых \\
\hline
\end{tabular}




\begin{tabular}{|c|c|c|c|c|}
\hline & $\begin{array}{l}315 \text { слияний; } \\
\text { США }\end{array}$ & $\begin{array}{l}\text { денежный поток до } \\
\text { налогов к рыночной } \\
\text { стоимости активов (pre- } \\
\text { tax operating cash flow to } \\
\text { TMV) }\end{array}$ & $\begin{array}{l}\text { деятельности до } \\
\text { сделки; отрасль; } \\
\text { размер компаний }\end{array}$ & $\begin{array}{l}\text { улучшений в } \\
\text { операционной } \\
\text { эффективности компаний }\end{array}$ \\
\hline $\begin{array}{l}\text { Yeh, Hoshino, } \\
2001\end{array}$ & $\begin{array}{l}\text { 1970-1994; } \\
86 \text { приобретений; } \\
\text { Япония }\end{array}$ & ROE, ROA & Отрасль & $\begin{array}{l}\text { M\&A с участием кейрецу } \\
\text { ведут к значимому } \\
\text { снижению ROE, ROA; } \\
\text { M\&A с участием } \\
\text { независимых фирм - нет }\end{array}$ \\
\hline Heron, Lie, 2002 & $\begin{array}{l}\text { 1985-1997; } \\
859 \\
\text { приобретений, } \\
\text { США }\end{array}$ & $\begin{array}{l}\text { Операционная прибыль к } \\
\text { выручке (operating } \\
\text { income to sales) }\end{array}$ & $\begin{array}{l}\text { Отрасль; } \\
\text { операционные } \\
\text { финансовые } \\
\text { показатели до } \\
\text { сделки }\end{array}$ & $\begin{array}{l}\text { Рост операционной } \\
\text { эффективности; метод } \\
\text { платежа не несет } \\
\text { информации о будущей } \\
\text { операционной } \\
\text { эффективности } \\
\text { компаний-покупателей }\end{array}$ \\
\hline $\begin{array}{l}\text { Sharma, Ho, } \\
2002\end{array}$ & $\begin{array}{l}1986-1991 ; \\
36 \text { слияний; } \\
\text { Австралия }\end{array}$ & ROA, ROE, PM, EPS & $\begin{array}{l}\text { Отрасль; размер } \\
\text { компаний }\end{array}$ & $\begin{array}{l}\text { для компаний- } \\
\text { покупателей более } \\
\text { низкие показатели } \\
\text { операционной } \\
\text { эффективности } \\
\end{array}$ \\
\hline $\begin{array}{l}\text { Powell, Stark, } \\
2005\end{array}$ & $\begin{array}{l}\text { 1985-1993; } \\
191 \text { поглощений; } \\
\text { Великобритания }\end{array}$ & $\begin{array}{l}\text { Операционный } \\
\text { денежный поток к } \\
\text { рыночной стоимости } \\
\text { активов или рыночной } \\
\text { стоимости активов } \\
\text { скорректированных на } \\
\text { реакцию рынка или } \\
\text { балансовой стоимости } \\
\text { активов или выручке } \\
\text { (operating cash flow to } \\
\text { TMV or TMV adjusted for } \\
\text { market reaction to the } \\
\text { takeover or BV assets or } \\
\text { Sales) }\end{array}$ & $\begin{array}{l}\text { Отрасль; } \\
\text { операционные } \\
\text { финансовые } \\
\text { показатели до } \\
\text { сделки; размер } \\
\text { компании }\end{array}$ & $\begin{array}{l}\text { Значимые улучшения в } \\
\text { операционной } \\
\text { эффективности компаний }\end{array}$ \\
\hline $\begin{array}{l}\text { Martynova, } \\
\text { Oosting, } \\
\text { Renneboog, } 2006\end{array}$ & $\begin{array}{l}\text { 1997-2001; } 155 \\
\text { приобретений; } \\
\text { Европа }\end{array}$ & $\begin{array}{l}\text { EBITDA -оборотный } \\
\text { капитал или ЕВITDA к } \\
\text { балансовой стоимости } \\
\text { активов, выручке; } \\
((\text { EBITDA - WC) to } \\
\text { BVassets , } \\
\text { (EBITDA - WC) to Sales, } \\
\text { EBITDA to BVassets, } \\
\text { EBITDA to Sales) }\end{array}$ & Отрасль & $\begin{array}{l}\text { Компании-участницы } \\
\text { сделки более } \\
\text { эффективны, чем } \\
\text { компании-аналоги до } \\
\text { сделки, а после нее } \\
\text { снижение операционной } \\
\text { эффективности у } \\
\text { компаний-покупателей, } \\
\text { которое становится } \\
\text { незначимым после } \\
\text { контроля за } \\
\text { эффективностью } \\
\text { деятельности компаний- } \\
\text { аналогов } \\
\end{array}$ \\
\hline $\begin{array}{l}\text { Devos, } \\
\text { Kadapakkam, } \\
\text { Krishnamurthy, } \\
2008\end{array}$ & $\begin{array}{l}\text { 1980-1996; } \\
264 \\
\text { приобретений, } \\
\text { Великобритания }\end{array}$ & $\begin{array}{l}\text { Дисконтированный } \\
\text { денежный поток на } \\
\text { капитал } \\
\text { (discounted capital cash } \\
\text { flows) } \\
\end{array}$ & & $\begin{array}{l}\text { Рост показателей } \\
\text { операционной } \\
\text { эффективности на } \\
10,03 \% \text { в результате } \\
\text { слияний } \\
\end{array}$ \\
\hline
\end{tabular}

TMV = рыночная стоимость активов $\mathrm{ROE}=$ доходность собственного капитала (return on equity)

(total market value of assets) $\quad$ ROA = доходность активов (return on assets)

BV assets = балансовая стоимость $\mathrm{PM}=$ рентабельность продаж (profit margin)

активов (book value of assets) $\quad$ EPS = прибыль на акцию (earnings per share)

$\mathrm{BV}$ equity = балансовая стоимость $\mathrm{WC}=$ оборотный капитал (working capital)

собственного капитала (book value

of equity) 


\section{Список литературы}

1. Григорьева С.А. Эффективность стратегий диверсификации компаний на развивающихся рынках капитала // Корпоративные финансовые решения. Эмпирический анализ российских компаний. Под науч. редакцией Ивашковской И.В. М.: Инфра-М, 2011. С. 80-112.

2. Чиркова Е.В., Чувствина Е.В., Исследование факторов, влияющих на инвестиционную активность компании // Корпоративные финансы. 2011. №3(19) С. 5-18. URL: http://cfjournal.hse.ru/data/2011/11/07/1272275842/CFJ19 5 18 Черкасова Теплова_pdf

3. Anslinger, P.L., Copeland, T. (1996), Growth through Acquisitions A Fresh Look, Harvard Business Review, 1 (1996).

4. Baker, R.D., Limmack, R.J. (2002), UK takeovers and acquiring company wealth changes: the impact of survivorship and other potential selection biases on post-outcome performance, University of Stirling Working paper, May (2002).

5. Bartels, J., Douwes, R., M. de Jong, Pruyn, A. (2006), Organizational identification during a merger: Determinants of employees expected identification with the new organization, London, British Journal of Management, 17 (2006) 76-112.

6. Beena, P.L. (2004), Towards understanding the merger wave in the Indian corporate sector a comparative perspective, Working paper 355 (2004) 1-44.

7. Betton, S., Eckbo, B.E. Thorburn, K.S. (2008), Massive wealth destruction? Bidder gains revisited, Working paper, Tuck School of Business at Dartmouth.

8. Billett, T.M., Mauer, D.C. (2003), Cross-Subsidies, External Financing Constraints, and the Contribution of the Internal Capital Market to Firm Value, The Review of Financial Studies, 4(16) (2003) 1167-1201.

9. Bradley, M., Sundaram, A. (2006), Acquisitions and performance: a re-assessment of the evidence, Working paper, Duke University.

10. Bruner, R.F. (2001), Does M\&A Pay? A Survey of Evidence for the Decision-Maker, Darden Graduate School of Business, University of Virginia.

11. Campa, J.M., Hernando, I. (2004), Shareholder Value Creation in European M\&As, European Financial Management, 1(10) (2004) 47-81.

12. Cartwright, S. (2005), Mergers and acquisitions: An update and appraisal, in: G.P. Hodgkinson and J.K. Ford (eds.), International Review of Industrial and Organizational Psychology, 20 (2005) 1-38.

13. Changqi, W., Ningling, X. (2010), Determinants of Cross-Border M\&A Performance of Chinese Enterprises, Procedia Social and Behavioral Science, 2(2010) 6896-6905.

14. Devos, E., Kadapakkam, P-R., Krishnamurthy S. (2009) How do mergers create value? A comparison of taxes, market power, and efficiency improvements as explanations for synergies, The Review of Financial Studies, 22 (2009).

15. Eckbo, E., Thorburn, K. (2000), Gains to Bidder Firms Revisited: Domestic and Foreign Acquisitions in Canada, Journal of Financial and Quantitative Analysis, 35 (2000) 1-25.

16. Ghosh, A. (2001), Does operating performance really improve following corporate acquisitions? Journal of Corporate Finance, 7 (2001) 151-178.

17. Glegg, C., Harris, O. Buckley W. (2010), When does diversification add value: evidence from corporate governance and abnormal long-term stock performance, Corporate ownership \& control, 3(7) (2010) 325-342.

18. Goergen, M., Renneboog, L. (2003), Shareholder wealth effects of European domestic and cross-border takeover bids, Finance Working Paper.

19. Gregoric, A., Vespro, C. (2009), Block trades and the benefits of control in Slovenia, Economics of Transition, 17(1) (2009) 175-210.

20. Hackbarth, D., Morellec, E. (2008), Stock returns in mergers and acquisitions, Journal of Finance, 3(63) (2008) 1213-1252. 
21. Hamza, T. (2009), Determinants of short-term value creation for the bidders: evidence from France, Journal of Management and Governance, 15 (2009) 157-186.

22. Haslam, S.A., Ellemers, N. (2005), Social identity in industrial and organizational psychology: Concepts, controversies and contributions, in: G. P. Hodgkinson and J. K. Ford (eds.), International Review of Industrial and Organizational Psychology, 20 (2005) 39118.

23. Healy, P.M., Palepu, K.G., Ruback, R.S. (1992), Does corporate performance improve after mergers? Journal of Financial Economics, 31 (1992) 135-175.

24. Herman, E., Lowenstein, L. (2008), The efficiency effects of hostile takeovers, in: Coffee J.C., Lowenstein Jr., L., and S. Rose-Ackerman (eds). Knights, Raiders and Targets. New York: Oxford University Press. P. 211-240.

25. Heron, R., Lie, E. (2002), Operating performance and the method of payment in takeovers, Journal of Financial and quantitative analysis, 1(37) (2002) 137-155.

26. Ho-Mou Wu (2009), Merger Activities and Stock Market Valuation in China Chapter, in: Takatoshi Ito and Andrew K. Rose (eds). NBER book Financial Sector Development in the Pacific Rim, East Asia Seminar on Economics, 18 (2009) 241-260.

27. Khanna, T., Palepu, K. (1997), Why Focused Strategies May Be Wrong for Emerging Markets, Harvard Business Review, (1997) 41-51.

28. Loderer, C., Martin, K. (1990), Corporate acquisitions by listed firms: the experience of comprehensive sample, Financial management, 19 (1990) 17-33.

29. Lu, Q. (2008), Do Stock Mergers Create Value for Acquires?, dissertation.

30. Manson, S., Stark, A., Thomas, H. (1994), A cash flow analysis of the operational gains from takeovers, Research report 35 of the Chartered Association of Certified Accountants, London.

31. Mantravadi, P., Reddy, A V. (2008), Post-merger performance of acquiring firms from different industries in India, International Research Journal of Finance and Economics, 22 (2008) 192-204.

32. Maquieria, C., Megginson W., Nail, L. (1998), Wealth Creation versus wealth redistributions in pure stock-for-stock mergers, Journal of Financial Economics, 48 (1998) $3-33$.

33. Martynova, M., Oosting, S., Renneboog, L. (2006), The long-term operating performance of European mergers and acquisitions, Finance working paper 137. URL: www.ecgi.org/wp.

34. Masulis, R.W., Wang, C., Xie, F. (2005), Corporate governance and acquirer returns, SSRN Working paper № 116.

35. Moeller, S. B., Schlingemann, F. P., Stulz, R. M. (2005), Wealth destruction on a massive scale? A study of acquisition firm returns in the recent merger wave, Journal of Finance, 60 (2005) 757-782.

36. Moeller, S.B., Schlingemann, F.P., Stulz, R.M. (2007), How do diversity of opinion and information asymmetry affect acquirer returns? Review of Financial Studies, 20 (2007) 2047-2078.

37. Pawaskar, V. (2001), Effect of mergers on corporate performance in India, Vikalpa, 1(26) (2001) 19-32.

38. Pop, D. (2006), M\&A market in transition economies: Evidence from Romania, Emerging Markets Review, 7 (2006) 244-260.

39. Powell, R.G., Stark, A.W. (2005), Does operating performance increase post-takeover for UK takeovers? A comparison of performance measures and benchmarks, Journal of Corporate Finance, 11 (2005) 293-317.

40. Ramaswamy, K.P., Waegelein, J.F. (2003), Firm Financial Performance Folowing Mergers, Review of Quantitative Finance and Accounting, 20 (2003) 115-126.

41. Ravencraft, D.J., Sherer, F.M. (1989), The profitability of mergers, International, Journal of Industrial Organization, 7 (1989) 110-116. 
42. Roll, R. (1986), The hubris hypothesis of corporate takeovers, Journal of Business, 59 (1986) 197-216.

43. Schoenberg, R. (2000), The influence of cultural compatibility within cross-border acquisitions: A review, in (ed.) 1 (Advances in Mergers \& Acquisitions, Volume 1), Emerald Group Publishing Limited. P. 43-59.

44. Schwert, G.W. (1996), Markup Pricing in Mergers and Acquisitions, Journal of Financial Economics, 41 (1996) 153-162.

45. Sharma, D.S., Ho, J. (2002), The impact of acquisitions on operating performance: some Australian evidence, Journal of Business Finance \& Accounting, 29 (2002) 155-200.

46. Sudarsanam, S. (2003), Creating value from mergers and acquisitions: the challenges, an international and integrated perspective. FT Prentice Hall.

47. Swanstorm, M. (2006), Corporate governance and the abnormal returns to acquisition announcements, Journal of Business Strategies, 2(23) (2006) 115-129.

48. Switzer, J.A., (1996), Evidence on real gains in corporate acquisitions, Journal of Economics and Business 48 (1996) 443-460.

49. Trojanowski, G. (2002), Equity block transfers in transition economies: evidence from Poland, CEPR Discussion Paper.

50. Tsung-Ming, Y., Hoshino, Y. (2000), The effects of mergers and acquisitions on Taiwanese corporations, Review of Pacific Basin Financial Markets and Polices, 2(3) (2000) 183-199.

51. Walker, M. (2000), Corporate Takeovers, Strategic Objectives, and Acquiring-firm Shareholder Wealth, Financial Management, (2000) 53-66.

52. Yeh, T.M., Hoshino, Y. (2002), Productivity and operating performance of Japanese merging firms: Keiretsu-related and independent mergers, Japan and the World Economy, 14 (2002) 347-366.

53. Yook, K.C. (2004), The Measurement of Post-Acquisition Performance Using EVA, Quarterly Journal of Business and Economics, 3/4(43) (2004) 67-83. 